\title{
重力波検出器における光スクイーズ技術の応用
}

\author{
宗宮 健太郎 \\ カリフォルニア工科大学 理論天文学教室 (MC 130-33, 1200 E California Blvd., Pasadena CA 91125, USA)
}

\section{Application of Optical Squeezing to Gravitational-Wave Detectors}

\author{
Kentaro SOMIYA \\ California Institute of Technology, MC 130-33, 1200 E California Blvd., Pasadena CA 91125, USA
}

(Received September 30, 2008)

\begin{abstract}
Reduction of quantum noise is one of the main subjects to improve the sensitivity of next-generation gravitational-wave detectors. The use of squeezing techniques is expected to contribute to the improvement, and more than a few ideas have been proposed and also experimentally demonstrated. This review article introduces (i) the utility of squeezed vacuum generated by a non-linear optical device, (ii) the squeezing effect in a gravitational-wave detector due to the opto-mechanical coupling, and (iii) frequency-dependent squeezing with a filter cavity proposed for third-generation detectors.
\end{abstract}

Key Words: Interferometer, Quantum measurement, Squeezing

\section{1. 量子雑音}

重力波検出を妨げる雑音源の一つに光子数の統計的な 摇らぎから生じる量子雑音がある. 次世代の光干渉計型 重力波検出器では, 観測する周波数带の多くで量子雑音 が検出感度を制限すると考えられており, 量子雑音の研 究とその低滅化はホットなテーマである，本章では量子 光学の分野で確立されたスクイーズ技術の重力波検出器 への応用, 干渉計自体が備えるスクイーズ効果, などを 最新の情報をふまえて紹介する. 量子論研究の産物であ るスクイーズ技術が, 相対論研究の代表格である重力波 検出に貢献する，という点にも喜びを感じながら読んで いただければと思う。

重力波検出器はマイケルソン干渉計をダークフリンジ にして重力波信号を取得する，入射レーザーと鏡の摇ら ぎの同相成分はレーザー側へ戻り, 重力波信号を含めた 差動成分がダークポートに現れる。量子雑音はダーク ポートに扔ける電場の摇らぎに起因する。零光子状態の 固有関数は消滅演算子であるから, ダークポートの電場 (真空場) は以下の式で表される1)

$$
\hat{E}_{i n}(t)=\int_{0}^{\infty} \sqrt{\frac{2 \pi \hbar \omega_{0}}{A c}} \hat{a}_{\omega} e^{-i \omega t} \frac{d \omega}{2 \pi}
$$

ここでAはビームの断面積である. 自乗検波して零光子 状態での期待值をとると, 生成消滅演算子の交換関係：

$$
\left[\hat{a}_{\omega}, \hat{a}_{\omega^{\prime}}^{\dagger}\right]=2 \pi \delta\left(\omega-\omega^{\prime}\right)
$$

から, 真空場の摇らぎはゼロにならない。これが量子雑 音の起源となる。

重力波信号は，入射したキャリア光に対する位相変調 として，その上下の周波数に側帯波を形成する. 異なる 周波数に扔ける真空場は無相関であり, 各々が雑音源と なるわけであるが，上下の真空場を同相成分と差動成分 に変換して扱うと都合がよい. Fig. 1に示すように，周

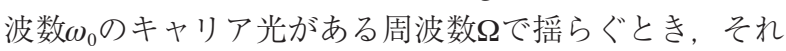
は光子数の摇らぎ(同相成分) と位相の摇らぎ (差動成分) に分けることができ，それぞれ別の経路で雑音をもたら
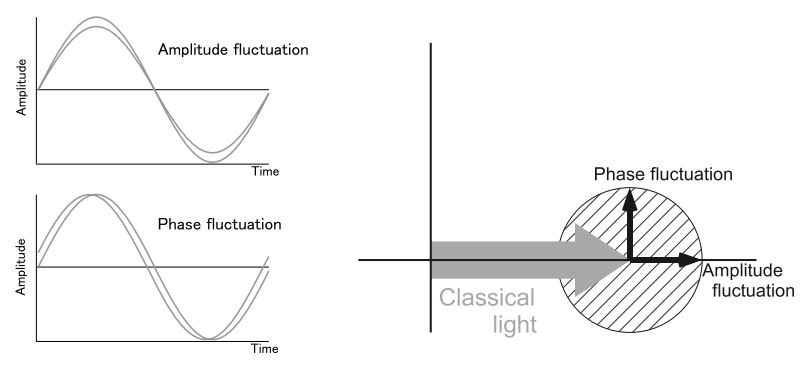

Fig. 1 Quantum noise consists of fluctuation of the number of photons and fluctuation of the phase. Filling the area where the probability density is higher than a certain value, we obtain a circle as shown above for a coherent field. 
すのである。

同相成分と差動成分を直交軸にとって位相空間で議論 をすると便利である(同図右)。重力波信号は位相方向 (phase quadrature)に現れるから, 重力波検出にとって真 空場の差動成分は直に雑音となる。これをショットノイ ズと呼んでいる。信号と直交する amplitude quadratureに 現れる真空場は，干渉計内におけるキャリアのパワーを 変化させ, 輻射圧によって鏡を差動に摇らし, 位相雑音 をもたらす。この輻射圧雑音とショットノイズを合わせ て量子雑音と呼ぶ.

ダークポートから干渉計に入射する真空場の同相成分 $\hat{a}_{1}(\Omega)$ と差動成分 $\hat{a}_{2}(\Omega)$ は以下のように表される：

$$
\hat{a}_{1}(\Omega)=\frac{\hat{a}_{\omega_{0}+\Omega}+\hat{a}_{\omega_{0-\Omega}}^{\dagger}}{\sqrt{2}}, \quad \hat{a}_{2}(\Omega)=\frac{\hat{a}_{\omega_{0}+\Omega}-\hat{a}_{\omega_{0-\Omega}}^{\dagger}}{\sqrt{2} i} .
$$

自乗して期待值をとると同じ大きさである。レーザー光 がコヒーレント状態にあることを表している，以下，・ および $(\Omega)$ は省略し，また，2つのquadratureを基底に とってベクトル表示することにする. 腕共振器を備えた マイケルソン干渉計との相互作用を求めると, 干渉計か ら出てくる真空場は以下のようになる：

$$
\left(\begin{array}{l}
b_{1} \\
b_{2}
\end{array}\right)=\left(\begin{array}{cc}
1 & 0 \\
-K & 1
\end{array}\right)\left(\begin{array}{l}
a_{1} \\
a_{2}
\end{array}\right) e^{2 i \beta}+\frac{\sqrt{2 K}}{h_{S Q L}}\left(\begin{array}{l}
0 \\
h
\end{array}\right) e^{i \beta}
$$

ここで，Kはレーザーパワーなどに比例する係数， $\beta$ は 干渉計を片道通過する際の位相遅れ，hは重力波による 腕の歪みである。古典的雑音は無視する。重力波信号が 現れるphase quadratureで量子雑音の大きさを歪みに換算 して表すと.

$$
h_{n}=h_{S Q L} \sqrt{\frac{K^{2}+1}{2 K}}
$$

となり，レーザーパワーに関わらず，雑音レベルがある 值を超えないことが分かる. その限界值は以下の式で与 えられ,

$$
h_{S Q L}=\sqrt{\frac{8 \hbar}{m \Omega^{2} L^{2}}}
$$

これを標準量子限界と呼ぶ。ここでれはプランク定数, $m$ は鏡の質量, $L$ は干渉計の基線長である。量子雑音の 研究は，この標準量子限界をどうすれば超えることがで きるのかをテーマとしてきたと言える。結論としては, さまざまな方法でこの限界を超えることが可能であるこ とが理論的に分かっており，これはむしろ「標準的な考 え方では超えられないと思いそうな限界值」と言っても いいかもしれない.

平成20年現在, 標準量子限界に到達した実験例は報告 されていない. 式(6)が示すように, 標準量子限界は周 波数が低いほど高くなるが, 低周波では熱雑音などの古 典的雑音も大きく, 観測が䩦しくなる。 また, 測定対象 の質量が小さいほど高くなるが，質量の小さな物体ほど 古典的雑音が大きい傾向にあり，これまた厳しくなる。
しかし, 軽くて熱雑音の小さな材料の開発などこの分野 の進展は著しく, 数年以内には最初の観測例が報告され るであろうと思われる.

ところで, 位置と運動量の不確定性関係によって感度 が制限されることはないのであろうか。実はこれまでの 議論に鏡の初期位置をあえて登場させなかった。鏡の初 期位置は，測定精度を上げようとすると初期運動量によ る反発を受けて逆に測定制度が落ちる。位置と運動量の 不確定性による量子限界が存在するのである。しかし， 重力波検出器の測定対象は実際には鏡の初期位置ではな く，熱雑音などと同じく，鏡に作用する古典的な力であ る。古典的な力の雑音は時間と共に蓄積し, 鏡の初期位 置と初期運動量を覆い隠してしまう。重力波検出におい ては初期情報は完全に失われていると考えてよい2)。逆 に初期位置と初期運動量を観測してその量子的振る舞い を調べることは，干渉計の感度を標準量子限界に到達さ せる以上に難しいということになるが, 不確定性原理の 直接的な検証として注目される新しい研究分野である.

\section{2. 非線形光学素子を用いたスクイーズ}

不確定性原理の要請から, ある周波数における $a_{1}$ と $a_{2}^{\dagger}$ の交換関係はその最小值が決まってしまうが，そのバラ ンスを変えることでショットノイズと輻射圧雑音のどち らかを減らすことができる(もう片方は逆に増えること になる)，本節ではまず単純にショットノイズを減らす ことに焦点をあてる．現行の重力波検出器では輻射圧雑 音が感度を制限するほどの高出力レーザーを導入してい ないため，ショットノイズを減らす方向にバランスを変 えることには利点が存在するのみである.

式(3)を見ると, 真空場がコヒーレント場であるのは, 和周波と差周波の真空場が相関を持たないからであるこ とが分かる。もし相関をもたらすことができれば，自乗 検波する際に，相関部分の符号に応じて同相成分と差動 成分のどちらかはコヒーレント場の期待值より大きく, もう一方は小さくなることになる。

相関をもたせる一つの方法が, 非線形光学素子にキャ リア光とその倍波を入射するというものである. Fig. 2 に示すように, キャリア周りにある和(差)周波の真空場 と倍波のビートは差(和) 周波と同じ周波数になり, 各々 の間に相関が生まれることになる。転非対称性をもつ 特殊な結晶に電場Eを入射し，ある位相整合条件を満た

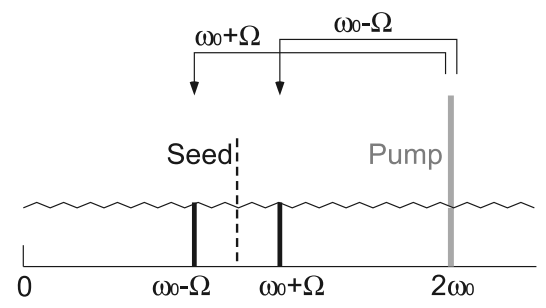

Fig. 2 Vacuum fields around the carrier light beat with the pump light at $2 \omega_{0}$ and this interference generates a correlation between the two vacuums. 
すと, 光パラメトリック発振という現象を起こすことが でき, 結晶内部の電気分極に二次の項が現れる：

$$
P=\varepsilon_{0}\left(\chi^{(1)} E+\chi^{(2)} E^{2}+\cdots\right)
$$

ここで $\varepsilon_{0}$ は真空の誘電率である。キャリアとその倍波を 入射すると, それらのビートが非線形分極率 $\chi^{(2)}$ に比例 して生み出されることになる。このときのキャリア光を シード光, 倍波をポンプ光と呼ぶ. ちなみに, シード光 が存在するとポンプ光周りの真空場とビートして無相関 な真空場を足してしまうので, シードは光でなく真空場 である方がよい. 強いスクイーズを生成できる非線形光 学結晶として $\mathrm{KTiOPO}_{4}$ が最近よく用いられる ${ }^{3)}$. 結晶は 共振器内に入れられ, ポンプ光とシードを共振させ, 非 線形効果を増幅させる，スクイーズの強さは，デシベル (dB) で表すことが多い. 光学損失がないとすれば, $6 \mathrm{~dB}$ のクイーズでショットノイズはおよそ半分に, $20 \mathrm{~dB}$ で10分の1になる。

重力波検出器用のスクイーズ実験として最初に登場し たのは豪州のグループによるもので, 波長1064 nmの連 続光を用い, スクイーズの大きさは約 $3 \mathrm{~dB}$, 実現した周 波数は約 $5 \mathrm{MHz}$ であった ${ }^{4)}$ ，その後の数年間におけるス クイーズ実験の進展は日進月歩で, ドイツのグループが 重力波検出帯域をカバーする $10 \sim 10 \mathrm{kHz}$ の範囲で4 $\mathrm{dB}$ のスクイーズを実現し ${ }^{5}$, 米国のグループが実際のプロ トタイプ干渉計でスクイーズ場を利用して感度を向上さ せる実験を行なった ${ }^{6)}$. 最新の実験結果では10 dBのス クイーズが実現できている77. Fig. 3にいくつか実験結果 を示す。来年にはドイツの重力波検出器GEOに, 2011 年には世界最高感度の重力波検出器である米国のLIGO にスクイーズを導入する話が進んでおり, 第三世代の技 術と言われたスクイーズが，第二世代ですでに採用され る可能性が出てきている.

さて, スクイーズにとって最大の敵は光学損失であ る. 共振器内で光を蓄積することによる信号の増幅は, 光学損失の増幅も同じ程度だけ伴う。鏡の位置を調整し て，ある周波数で重力波信号の増幅を最大にすると， ダークポートから入射する同じ周波数の真空場は共振器 内で失われ，それと同じ大きさをもった損失真空場が ショットノイズを生み出すため, スクイーズの効果は全 く見えなくなる.キャリアのパワーは同じとして, 仮に 共振器を用いずに無限大に近い強さのスクイーズを入れ た場合と比較してみると, ショットノイズのレベルはほ ぼ同じになる。ただし，スクイーズが広帯域でショット ノイズを改善する一方で, 共振器による信号増幅は周波 数を特定しなければならないから，スクイーズの方が利 点があると言える。実際にはスクイーズの大きさは有限 であるから, 光共振とスクイーズの組み合わせ方を最適 化することが必要となる。

光学損失は, スクイーズ場を最小不確定状態ではなく してしまう。スクイーズしたquadratureは損失が支配的 で，それと直交するquadratureではアンチスクイーズ場 が支配的となる。輻射圧雑音が干渉計感度に現れる状況
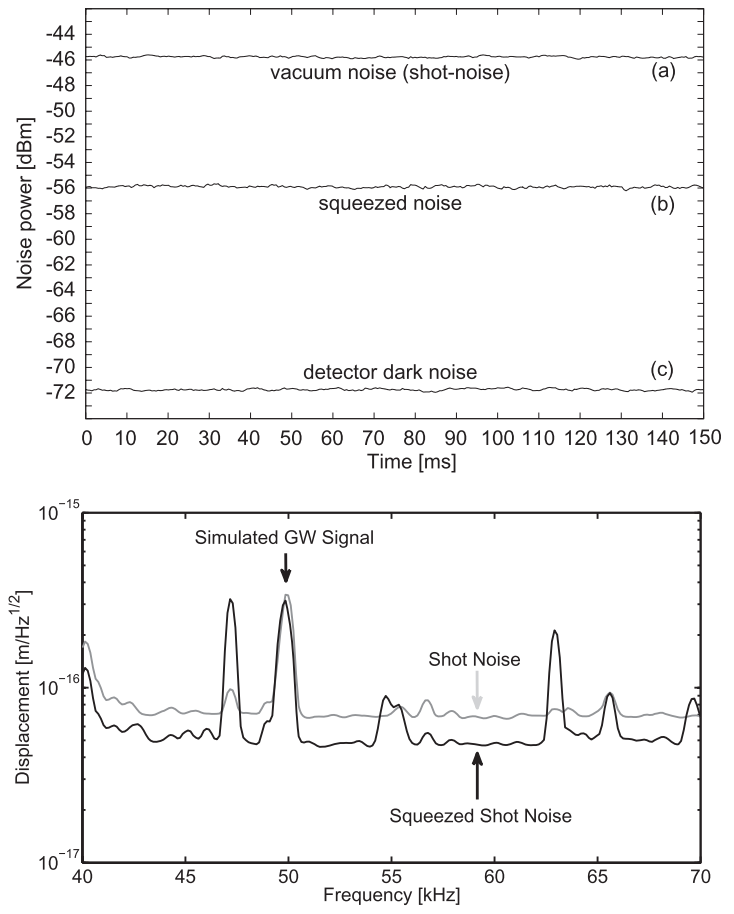

Fig. 3 Top: Demonstration of $10 \mathrm{~dB}$ squeezing at the University of Hannover. ${ }^{7)}$ The squeezing is realized down to $1 \mathrm{~Hz}$ due to their effort in reducing classical light. Bottom: Squeezing experiment at Caltech. ${ }^{6}$ The squeezed vacuum was injected to a prototype of a gravitational-wave detector and the sensitivity was improved at high frequencies.

下では, 最小不確定状態でないのは好ましくなく, スク イーズの度合いはスクイーザーの最大能力ではなく干渉 計の光学損失に合わせて選択されるべきである. スク イーズに周波数特性をもたせることでこの問題を回避す ることも可能であるが, 周波数特性については輻射圧雑 音の説明をした後で紹介する.

\section{3. ポンデロモーティブスクイーズ}

これまでに紹介したスクイーズとは全く違った方法で 生成されるスクイーズを紹介しよう。実は，干渉計内部 では, 真空場の同相成分が輻射圧雑音という位相雑音に 変換されることで, キャリア光の上下周波数の真空場に 相関が生まれており，結果としてスクイーズを生じるこ とが理論的に分かっている。そして，このポンデロモー ティブスクイーズ ${ }^{8)}$ と呼ばれる現象をうまく利用するこ とで，標準量子限界を超えることが可能なのである.

コヒーレントな真空場を干渉計のダークポートから入 射すると, 出力する真空場は式(4)に従い, Fig. 4のよう になる。信号を最大にする $b_{2}$ 軸上でSN比をとると標準 量子限界を超えられないが, 楕円の薄いところで信号取 得をすると違った結果を得られる。式(4)の2つの quadratureを組み合わせて, $b_{\zeta}=b_{1} \cos \zeta+b_{2} \sin \zeta て ゙$ 信号 を取得すると, 歪み感度は 


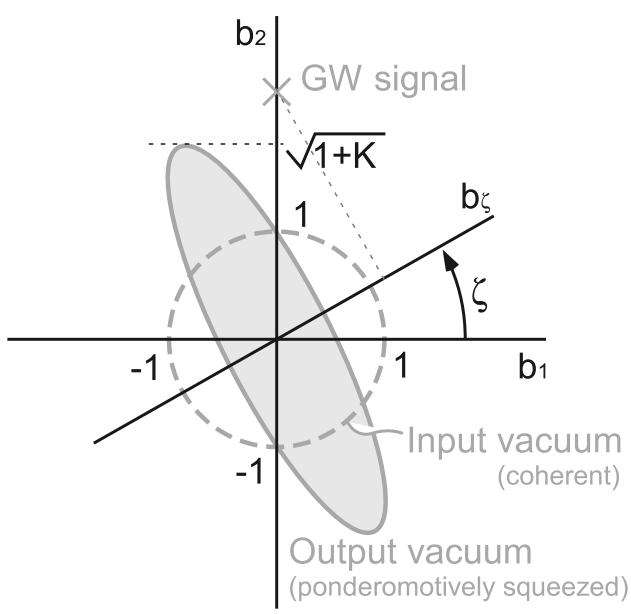

Fig. 4 While the input vacuum field is coherent (dashed circle), the output field from the interferometer is squeezed by the radiation-pressure effect (solid ellipse). By tuning the readout qudrature, the signalto-noise ratio to gravitational waves becomes better than that in the $b_{2}$ quadrature.

$$
h_{\varsigma}=h_{S Q L} \cdot \sqrt{\frac{(K-\cot \zeta)^{2}+1}{2 K}}
$$

となる。すなわち $\zeta=\operatorname{arccot} K て ゙$ 信号取得をすれば輻射圧 雑音が現れないことになる。ただし，Kは周波数依存性 のある量であり，らを1つに固定すると，輻射圧雑音が なくなるのは特定の周波数のみである.

現在の重力波検出器では, 位相変調側帯波を参照光に している(ヘテロダイン)ため, 信号取得のquadratureが $b_{2}$ に固定されている。これを変えるには，位相変調に強 度変調側帯波を加えるか99, キャリア光に位相差を加え たものを参照光にする(ホモダイン)ことが必要になる。 前者を含めたへテロダイン検波法では, 復調時に倍波周 波数の真空場が混ざる影響を取り除くための工夫が必要 になる ${ }^{10)}$ ，後者については，キャリアを干渉計の外に ピックオフして位相差をつけてから干渉計出力と干渉さ せるbalanced-homodyne法(Fig. 5) と, 干涉計の両腕の不 均衡により漏れ出すキャリアと同じ周波数の光を参照光 にするDC-readout法 ${ }^{11)}$ があり，どちらも同様の効果が期 待できる。

ポンデロモーティブスクイーズを利用して輻射圧雑音 を除去するのは，量子制御をしているに他ならない，輻 射圧杂隹音は入射真空場の同相成分 $a_{1}$ に起因しているか ら，その值を測定すれば輻射圧雑音の大きさが分かる。 例えば干渉計に入射する前に $a_{1}$ だけを光検出器で測定し ようとすると，量子性が破壊されてしまうが，信号およ び輻射圧雑音と同時に $a_{1}$ の大きさを測ることができれ ば，量子性を保ったまま $a_{1}$ を打ち消すことができる。信 号取得のquadratureを $b_{2}$ 軸から傾けるということは， $b_{1}$ が 含む $a_{1}$ 成分を $b_{2}$ に現れる輻射圧雑音と同時に測定してい ることを意味し，上記の量子制御が実現できるのであ る.

ポンデロモーティブスクイーズの検証実験は日本や米

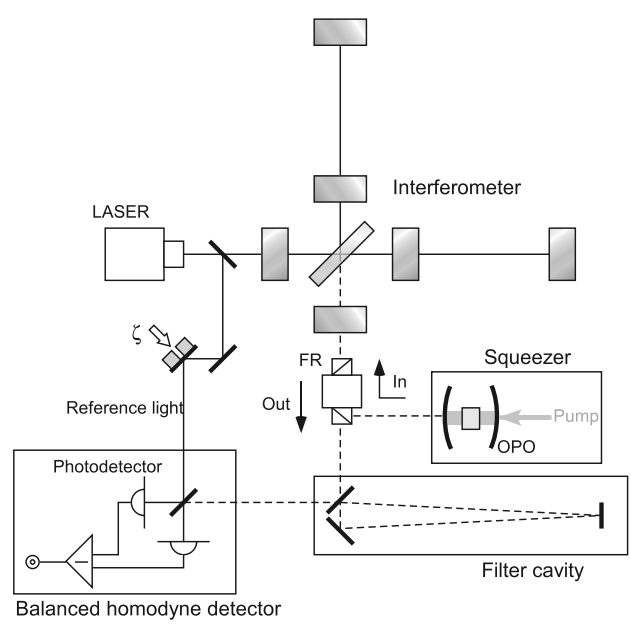

Fig. 5 Sketch of a next-generation gravitational-wave detector with squeezing techniques. (i) A squeezed vacuum generated by a non-linear crystal is injected to the interferometer through a Faraday rotator, (ii) the output field is squeezed differently at each frequency so that it is converted to white noise by a filter cavity, and (iii) the signal and noise are compared with the reference light from the laser in the optimal quadrature.

国などで行なわれており，数年以内には成功例が報告さ れると思われる，MITのグループでは，1gほどの鏡で干 渉計を組み，そのポンデロモーティブスクイーズされた 出力場を重力波検出器に入射する，というアイデアを提 唱し，実験を行なっている ${ }^{12)}$ 。結晶を用いたスクイーズ の方が一歩先んじているのは否めないが，面白い試みだ と言えるだろう。

\section{4. 周波数依存型スクイーズ}

ポンデロモーティブスクイーズが周波数依存性をもつ ため，スクイーズ真空場を入射するにしろ，らを変える にしろ，標準量子限界を超える感度が実現できるのは， 選択した周波数付近の狭い带域に限られる (Fig. 6に各々 の量子雑音スペクトルを示す)。この問題を解決するた め, 光共振器の出力に周波数応答があることを利用し たフィルターキャビティというアイデアが提唱されて いる ${ }^{1)}$. Fig. 5のように干涉計の出力ポートに共振器を配 置し, $\cot \zeta=K$ を全周波数で満たすような理想的なフィ ルターが実現できれば，Fig. 6上段の破線で示すような， 輻射圧雑音が全く現れない感度曲線を得ることができ る。また，スクイーザーの後でフィルターすれば，Fig. 6 下段の破線のような感度曲線を得ることができる. ショットノイズが支配的な周波数帯ではスクイーズを， 輻射圧雑音が支配的な周波数帯ではアンチスクイーズを 入射するわけである。

実際は，Kがポールを4つもった関数なので，理想的 なフィルターを実現するには, Fig. 5に示したような単 純な共振器ではなく，複数の共振器が必要になる ${ }^{13)}$ 。 ま た，低周波にポールをもつ共振器をつくるには，光の滞 

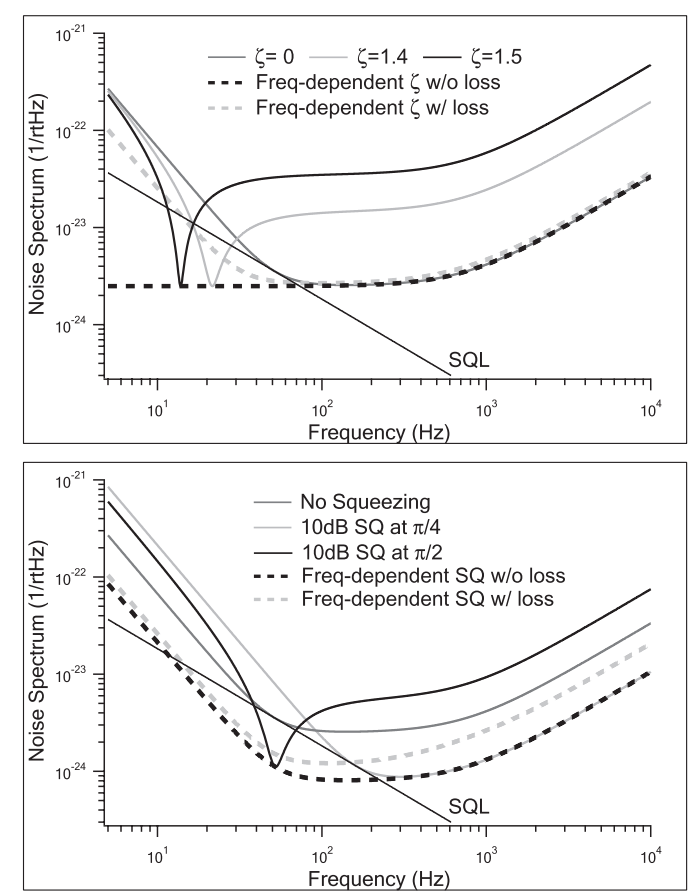

Fig. 6 Quantum noise spectra with the readout quadrature $\zeta$ being tuned (top), and with the squeezing angle being tuned (bottom). The sensitivity can be improved in broadband if these values are optimally chosen at each frequency using the filter cavity. Here the parameters are those for Advanced LIGO, a second-generation detector in USA.

在時間を長くしないといけないが, フィルターの光学損 失はスクイーズ効果を妨げるため, 共振器内で何度も反 射させることは許されず，基線長の大きなフィルターが 要求される.

ところで, 標準量子限界を超える方法の一つに, 光バ ネを用いた干渉計がある. 共振器内の鏡のマクロな位置 を調整すると, 鏡のミクロな位置に比例した輻射圧が復 元力となり，バネを形成するのである。このバネの共振 周波数では，信号の増幅がポンデロモーティブスクイー ズの増幅よりも急であるため, 検出器感度が標準量子限 界を超える. 光バネは第二世代重力波検出器の技術とし て確立されているが, 実は光バネと結晶スクイーズをそ
のまま組み合わせると，複雑な周波数応答のためにスク イーズの利点が失われることが分かっており, フィル ターキャビティの重要性が再認識されている. 光バネに ついては，参考文献14)などを参照してほしい。

以上，スクイーズ技術を中心に重力波検出器における 量子雑音研究を紹介した。結晶を用いたスクイーズ生成 以外については，実験よりも理論が先行しているが，数 年以内と予想される量子的輻射圧雑音の検出が実現すれ ば，さまざまな理論の検証および新しいアイデアの実践 が可能となる。まさにこれから面白いフェーズへ突入す る研究分野である.

最後に，本原稿の執筆に際して協力してくださった UCLAの合田圭介博士と, 執筆者の支援元である日本学 術振興会に感謝の意を表したいと思います。

\section{参考文献}

1) H. J. Kimble, Y. Levin, A. B. Matsko, K. S. Thorne, and S. P. Vyatchanin: Phys. Rev. D 65 (2001) 022002.

2) V. B. Braginsky, M. L. Gorodetsky, F. Ya. Khalili, A. B. Matsko, K. S. Thorne, and S. P. Vyatchanin: Phys. Rev. D 67 (2003) 082001.

3) T. Aoki, G. Takahashi, and A. Furusawa: Opt. Express, 14, (2006) 6930 ; K. Goda, E. E. Mikhailov, O. Miyakawa, S. Saraf, S. Vass, A. Weinstein, and N. Mavalvala: Opt. Lett. 33 (2008) 92.

4) K. McKenzie, D. A. Shaddock, D. E. McClelland, B. C. Buchler, and P. K. Lam: Phys. Rev. Lett. 88 (2002) 231102.

5) H. Vahlbruch, S. Chelkowski, B. Hage, A. Franzen, K. Danzmann, and R. Schnabel: Phys. Rev. Lett. 97 (2006) 011101.

6) K. Goda, O. Miyakawa, E. E. Mikhailov, S. Saraf, R. Adhikari, K. McKenzie, R. Ward, S. Vass, A. Weinstein, and N. Mavalvala: Nature Physics 4 (2008) 472.

7) H. Vahlbruch, M. Mehmet, S. Chelkowski, B. Hage, A. Franzen, N. Lastzka, S. Goßler, K. Danzmann, and R. Schnabel: Phys. Rev. Lett. 100 (2008) 033602.

8) V. B. Braginsky and A. B. Manukin: Sov. Phys. JETP 25 (1967) 653.

9) K. Somiya, Phys. Rev. D 67 (2003) 122001.

10) A. Buonanno, Y. Chen, and N. Mavalvala: Phys. Rev. D 67 (2003) 122005.

11) K. Somiya, Y. Chen, S. Kawamura, and N. Mio: Phys. Rev. D 73 (2006) 122005.

12) T. Corbitt, Y. Chen, F. Khalili, D. Ottaway, S. Vyatchanin, S.Whitcomb, and N. Mavalvala: Phys. Rev. A 73 (2006) 023801.

13) P. Purdue and Y. Chen: Phys. Rev. D 66 (2002) 122004.

14) A. Buonannno and Y. Chen: Phys. Rev. D 67 (2003) 062002; O. Miyakawa et al.: Phys. Rev. D 74 (2006) 022001.
ポンデロモーティブスクイーズ

(ponderomotive squeezing)

干渉計における光と鏡の相互作用によって生じるスク イーズ.コヒーレントな真空場はその振幅成分と位相成 分に相関がないという特徵をもつが，ポンプ光と共に干 渉計に入射すると振幅成分が輻射圧で鏡を摇らし，それ が位相変調をもたらすため, 出射するのは振幅成分と位 相成分に相関があるスクイーズ場となる，スクイーズを 引き起こした干渉計における鏡の位置測定では, 位相成 分に現れる輻射圧雑音を振幅成分の情報を用いて消去す
ることが可能である。また，軽量な鏡で構成した干渉計 で強力なスクイーズを生成し，その出力場を別の(大型) 干渉計に入射するという利用方法も提唱されている。こ のスクイーズは，輻射圧を介した相互作用であるため， 自由質点で構成された干渉計で生成すると，低周波ほど スクイーズが強いという特徴をもつ。 ちなみに2009年1 月現在，まだポンデロモーティブスクイーズを検出した 実験例は報告されていない.

(宗宮 健太郎) 